\title{
Articles
}

\section{Directives and Assessments in Japanese Native and Nonnative Conversation}

\author{
Yuri Hosoda \\ Kanagawa University
}

Various kinds of data and methodologies have been used to investigate nonnative speakers' (NNSs') pragmatic competence. In the past decade, attempts have been made to describe NNSs' pragmatic abilities in naturally occurring interaction using Conversation Analysis (CA) methodology. To date, there are an increasing number of CA studies that describe NNSs' pragmatic competence in institutional settings, but only a few in noninstitutional settings. Using the framework of CA, this study examines NNSs' pragmatic competence displayed in sequences of directives and assessments in casual native speaker (NS)-NNS conversation in Japanese. The analysis reveals that the pragmatic competence of the NNSs and NSs is constructed out of the detail of talk and other conduct in which the participants juxtapose multiple resources such as sequential organization, speech, body, and the surrounding environment to jointly shape the sequences of directives and assessments and establish mutual understanding in ongoing interaction.

これまで非母語話者の語用論的能力の検証が多くなされてきた。ここ10年間で特に盛ん に行われているのが、発話相互行為を会話分析法(conversational analysis)によって分析した 記述研究である。しかしながら、これまでに行われてきた研究の多くは学校の教室内など の発話の分析であり、自然な言語使用場面の会話の記述分析はあまり行われていない。本 研究は、母語話者と非母語話者の日常会話を指示(directive)および評価(assessment)の連鎖 (sequence)に焦点を置き、会話分析法を使って分析した。その結果、語用論的能力は会話 参与者同士が言語のみならず、会話の構造、ジェスチャー、場面などさまざまな情報に言 及し判断しながら、ともに理解を構築してゆく能力であるということが示された。

JALT Journal, Vol. 27, No. 1, May, 2005 
$\mathrm{T}$ o date, various data collection procedures have been used to investigate nonnative speakers' (NNSs') pragmatic competence. tion, conversation tasks, and interviews as data sources, while those that examine written data utilize production questionnaires, multiple choice questionnaires, rating-scales questionnaires, and diaries as data sources. In addition, think-aloud protocols that are used to elicit participants' verbalizations of thought processes may be used in combination with other tasks such as production questionnaires. Each data collection procedure has advantages and disadvantages (for further discussion of each procedure, see Kasper, 2000; Kasper \& Dahl, 1991, Kasper \& Rose, 2003). Furthermore, the methods for analyzing collected data also vary depending on researchers' disciplines. For example, data from naturally occurring interaction have attracted a number of researchers that employ microanalytic approaches such as language socialization (e.g., Ohta, 2000a; 2000b; Poole, 1992), ethnographic microanalysis (e.g., Fiksdal, 1990), and conversation analysis (e.g., Firth, 1996; Mori, 2002).

This study focuses on one way of examining naturally occurring interaction. Specifically, I will demonstrate how video-recorded naturally occurring interaction between native speakers (NSs) and NNSs can be analyzed using the framework of Conversation Analysis (CA). Into my analysis, I bring multiple resources available for the speaker (i.e., sequential organization, speech, body movements, and surrounding environment). Before I discuss the methodology and data for the present study, I will introduce some previous studies that discuss the relationships among gesture, speech, and pragmatics.

\section{Gesture, Speech, and Pragmatics: Psycholinguistic Perspective}

Previously, the relationships among body movements, speech, and pragmatics have been studied extensively from a psychological/cognitive perspective (e.g., Kelly, Barr, Church, \& Lynch, 1999; Kita, 2003; McNeil, 1985, 1992, 2003). These authors examined body movements in terms of how they correlate with the psychological functioning of a speaker's mind during the speaking process. In this line of research, a speaker's private and interpersonal psychological experiences are considered to be externalized as gestures.

Some authors focused on hand movements that co-occur with speech. For example, McNeil $(1985,1992,2003)$ investigated hand movements that occur during the process of speaking in narrations and dyadic interaction 
tasks. McNeil found that gesture and speech arise from a common cognitive source, and that gesture and speech together represent thought in performing semantic and pragmatic functions. Furthermore, Kelly et al. (1999) examined pragmatic functions of hand movements that co-occur with speech. They conducted a series of experiments in which subjects watched role-play videos and answered some comprehension questions. In some of the role-plays, the actors had matching hand movements and speech, and in some others, their hand movements did not match their speech. Kelly et al. found that certain gestures such as deictic (i.e., pointing) and iconic gestures have an important impact on how people comprehend and remember pragmatic functions in communication. For instance, one of their experiments showed that pointing gestures themselves can be recognized as indirect requests. The authors also demonstrated that speech and gesture interactively accomplish the meaning of communicative acts.

On the other hand, Kita (2003) emphasized the importance of paying attention to body movements such as torso movements and gaze that might otherwise be considered nonspeech related. Through experiments on direction giving, Kita found that gestures, including hand gestures, torso movements, and gaze, facilitate speech at the conceptual level and showed the possibility that all these communicative means are interlinked in the cognitive process underlying the performance of a pragmatic function.

Thus, psycholinguistic studies of gestures have shown the close ties between body movements and speech in carrying out and understanding pragmatic functions. Conversation Analysis (CA) methodology, which I will employ in this paper, also emphasizes the significance of examining both gesture and speech in understanding pragmatics. However, as I will discuss below, the CA approach is different from the psycholinguistic approach in that in CA practitioners examine gesture and body movements from the participants' perspectives; that is, rather than having researchers or observers interpret the speakers' gestures, CA practitioners focus on looking closely at how speakers as well as listeners publicly display the relevance of gesture and speech in the course of accomplishing actions in ongoing interaction.

\section{CA Methodology and Pragmatics}

CA emerged in reaction to mainstream American sociologists whose discipline imposed a priori theorization of social phenomena. From its earliest stage, CA analysts strongly cautioned against a priori theorization and ad hoc analytical categorization of social interaction. Instead, 
through repeated examination of tape recordings and transcripts of authentic spoken interaction, the analysts focused on revealing participants' displayed orientation to making sense of interactions, an orientation that is embodied in the detail of their talk and other conduct.

In this methodology, in attempting to understand what actions the speaker is performing in the talk (i.e. "speech acts" such as requesting, apologizing, complaining, complimenting, and offering), we are cautioned not to isolate each utterance from the sequence but rather to observe the organization of courses of action realized jointly by and for the parties of interaction through sequences of turns. Thus, we need to observe and understand how and why a certain action has come to be deployed by the speaker at that very moment, how the recipient shows understanding (or nonunderstanding) of the deployment, and what consequence the deployment and understanding (or nonunderstanding) have in the subsequent interaction. Participants' pragmatic competence to perform various actions is considered to be publicly displayed through the details of turns taken and yielded by the participants themselves in constructing the ongoing talk.

When we examine video-recorded naturally occurring interaction, we also need to consider the nonverbal signals sent, because in face-toface communication "interactants are normally visible for one another" (Streek, 1993, p. 275) and interactants use not only language but other resources such as gaze, posture, and local environment to accomplish actions in face-to-face interaction (Goodwin, 2000, 2003). Traditionally, conversation analysts have relied on audio recording for collecting data of talk-in-interaction. Therefore, much of the earlier work has been done on telephone conversation, which automatically eliminates interactants' orientation to each other's nonverbal behavior. However, ever since the development of technology made video cameras available to everyone, some CA researchers have used video cameras to collect data. Those studies which used video-recorded interactions as data revealed how speech and nonverbal behavior such as gaze and body movements are oriented to by the interactants with respect to the structural organization of talk-in-interaction (e.g., Goodwin, 1981; 2000, 2003; Goodwin \& Goodwin, 1986, 1987; Schegloff, 1984, 1998, 1999). It is important to note that even when interactants' nonverbal behavior is examined, CA's focus is still on the management of turn allocation and turn construction, and nonverbal features of speakers and hearers are examined only when the participants themselves have displayed their orientation to the nonverbal features in the interaction. 
CA has originally been applied only to conversation between NSs and has generated a number of studies that revealed NSs' pragmatic competence in ongoing interaction (e.g., Drew, 1984 on invitations; Goodwin \& Goodwin, 1987; Pomerantz, 1978 on compliments; Pomerantz, 1984 on assessments; Schegloff, 1988 on complaints). Some CA practitioners have recently started applying CA to the analysis of talk by NNSs, especially those in institutional settings such as educational settings (e.g., Carroll, 2000; Markee, 2000; Mori, 2002) and business encounters (e.g., Firth, 1996; Wagner \& Firth, 1997). However, there is still only a small number of CA studies that have described NNSs' pragmatic competence in noninstitutional settings (e.g., Wong, 1994; 2000a; 2000b).

In the remainder of this paper, I will use the CA framework to demonstrate how NNSs and their NS interlocutors display their pragmatic competence in collaboratively establishing mutual understanding through sequences of directives and assessments.

\section{Methods}

The data analyzed for this study are based on two video-recorded NS -NNS conversations between friends speaking in Japanese involving four individuals in all. The three sets of video-recorded data (two in conversation 1 and one in conversation 2) come from a larger set of data that consists of 15 sets of NS-NS conversation and 15 sets of NS-NNS conversation. ${ }^{1}$ Both conversations introduced in this study were recorded for approximately 30 minutes.

\section{Participants}

Of the four participants, two were Americans and the other two were Japanese. All were male; their ages ranged from the late 20 s to early 30 s. As the base language for the conversations was Japanese in the data, the two Americans were considered to be NNSs and the two Japanese were considered to be NSs. The two NNS participants, Bill and Gregg (pseudonyms), were native speakers of English who were advanced speakers of Japanese. Both of them had completed courses in teaching Japanese conducted in Japanese and offered in the graduate school of an American university in Tokyo. Both Bill and Gregg had been living in Japan for six years. Bill was a high school English teacher and Gregg was a college English teacher. One of the NS participants, Koma (pseudonym), was an English teacher at a language school, and the other NS participant, Taro 
(pseudonym), had just come back from a one-year working holiday program in Australia. ${ }^{2}$

\section{Procedures}

The researcher prepared for collecting the data by asking the American participants and their Japanese friends for permission to audio- and video record their conversations beforehand and then visiting the place where each dyadic conversation took place. The researcher arrived at the place before the conversation began in order to set up the camera. The conversation between Bill and Koma was recorded at Bill's office in the high school in November, 1999, and the conversation between Gregg and Taro was recorded at Gregg's residence in December, 1999. The participants were not given any topics prior to the conversation and were encouraged to talk freely about whatever they would normally talk about. They were, however, asked to remain within view of the camera. The camera was on a tripod placed about five feet away. In order to avoid the influence of the researcher on the setting or the participants (known as "reactivity," Maxwell, 1996), the researcher was not present while the conversations were being recorded. As for the influence of the video camera, the presence of the camera may not affect the naturalness of the data to a great degree. As Goodwin (1981) notes, the participants in face-to-face conversation never interact as if they are not observed; they organize their talk and other conduct in terms of their coparticipants' behavior. Moreover, the focus of CA studies is not the surface content of the interaction but the structural organization. Therefore, even when the participants talk about the recording procedure and equipment, the underlying structural organization of the interaction remains unaffected.

The two conversations were transcribed and analyzed by the researcher. Transcription and translation conventions were adapted from Jefferson (1984) and Maynard (1997) (see Appendix A for transcription conventions). In the discussion of the data below, I will focus my analysis on three directive sequences I found in the data.

\section{Results and Discussion}

In the data, the people who utter the directives are the NNSs of Japanese, Bill and Gregg. The three directives are all V (verb)-mite "Try V-ing" form of directives. The V-mite utterance is a directive in the sense that it is an utterance that a speaker uses to get someone else to do something 
and it expresses what the speaker wants (Searle, 1979), and its grammatical form is the imperative. However, my concern in this paper is not to examine the directive utterance in isolation, but rather to look at all the resources the participants orient to, and examine what understanding it took for the speaker to produce the directive, how the directive is understood by the recipient, and what consequences the recipient's understanding had in the subsequent turns.

\section{Overview of the Data}

The first directive sequence comes from the conversation between Bill and Koma. (See Appendix B for the full transcription of the three sequences.) As mentioned above, Bill and Koma conversed at Bill's office. The directive occurs after Koma mentions the heaviness of his notebook computer. Bill utters "Kore motte mite (Try lifting this up)" and Koma lifts up Bill's computer on Bill's desk. The second directive sequence also comes from the conversation between Bill and Koma. The directive occurs when Koma mentions the track pad on his notebook computer. Bill produces "Kore tsukatte mite (Try using this)" and Koma tries using the track pad on Bill's computer. The third directive sequence comes from the conversation between Gregg and Taro at Gregg's residence. The directive is produced by Gregg when Taro shows Gregg a musical instrument Taro brought home from Australia. Gregg utters "Yatte mite (Try doing)" and Taro starts playing the instrument.

An initial look at the three directive sequences reveals that there is a pattern in all three: the Japanese-NS recipient of the directives immediately follows the directive uttered by the NNS. In addition, some kind of assessment followed each directive and the compliance with the directive. In the first directive sequence, after Koma lifts the computer up, assessments concerning the heaviness of the computer are made. In the second directive sequence, while Koma is using the track pad on Bill's computer, Bill makes an assessment of the easiness of using the device and Koma makes a comment. In the third directive sequence, after Taro complies with the directive, some assessments concerning the sound of the instrument are made. In all three instances, the speaker and the recipient seem to have understood each other and a set of actions was carried out smoothly. How did they establish mutual understanding through the directive sequences? In order to address this question, I will look next at each instance in more detail. 


\section{Uttering the Directives}

In all three cases, the conversation leading up to the interaction and the immediate setting in which it takes place are relevant to the directive, and the relevance is shown in the directives themselves. In the first directive sequence, at the beginning, Koma is complaining about his Mac computer, which he thinks is too heavy to be called a notebook computer. After listening to Koma's complaints about the heaviness of his computer, Bill produces an utterance that directs Koma to lift up his computer which is behind Koma. In the second directive sequence, after Koma tells Bill that the track pad of Koma's notebook computer is not easy to use, Bill tells Koma to try using the one in his computer. In the third directive sequence, prior to the directive, Taro and Gregg are talking about the instrument Taro has brought to Gregg's residence, and just before Gregg tells Taro to play the instrument, Taro brings the instrument close to his mouth. Therefore, in all three cases, the speakers' directives are dependent on what was already being talked about and the immediate settings in which the talking took place (i.e., the availability of the objects at the moment of the utterances). In other words, the NNSs' directives show their competence in understanding what has been said thus far and the immediate environment in which the interaction is going on.

\section{Recipients' Understanding of the Directives}

As discussed above, the directives produced by the NNSs arose out of the preceding interaction and the immediate setting, and this may have been one of the main factors of the recipients' understanding of the directives. However, closer examination of the data revealed that the speakers not only drew upon these key elements, but also used their bodies to facilitate the recipients' understanding of the directives. Therefore, in this section, in order to discuss exactly how the recipients reached the understanding of the directives, I will show the process of making directives and complying with directives in detail. Consider the first directive sequence with nonverbal features. ${ }^{3}$

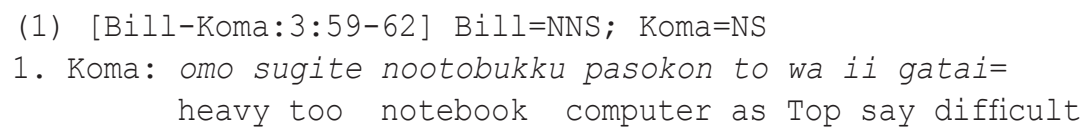


2. =tokoro ga aru $n$ da yo ne.= place Nom exist NR Cop IP IP

"It has got an element to say that it is too heavy to say it's a notebook computer."

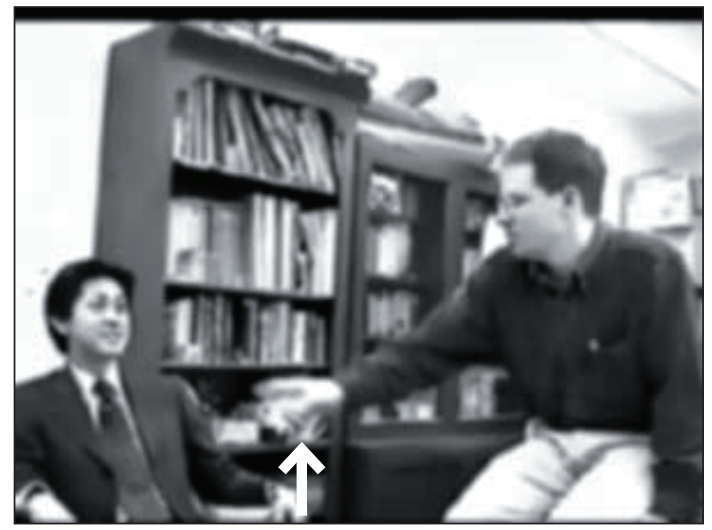

Figure 1. Bill starts preparing for a pointing gesture before he produces his directive.

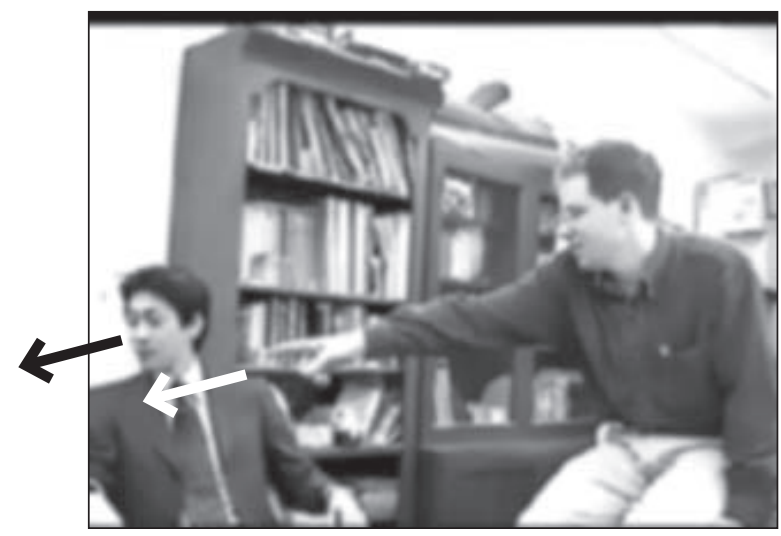

Figure 2. By the time Bill finishes producing motte, Koma starts turning his body orientation to the referent.

3. Bill: $=u: \mid$ n. $\mid$ tt ko $\mid$ re $\mid$ motte $\mid$ mite. Uh-huh this have try

"Uh-huh. Try lifting it up."

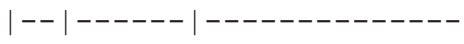



Bill: I( turns gaze to the object))
Bill: |((raises his arm))
Bill:
I ( gazing and pointing at the
object)!
Koma :
$|------|------$
I ( turns his gaze to the
Koma :
object))
I ( (turns his body
to the object))

4. Koma:|kore donogurai|aru | no.

this how much exist IP

"How much does this weigh?"

|-------------|----------

Koma:| ((turns his body completely facing the object))

Koma: I ( (moves both arms toward the

object) )

|-----------------|-----

Bill:|((points at the object))|((brings his arm down)

5. Bill:|kekkou omoi.

quite heavy
"It's quite heavy."
|----------

Koma: | ( leaning toward the object))

6. (.) ((Koma lifts the computer up))

In line 1, before Bill starts uttering a directive, he turns his gaze to the referent (i.e., his computer) while aligning with Koma's complaint by producing $u:: n$ at the turn-initial position. Bill then starts raising his arm to point to the referent while he is making a sound "tt": Bill starts preparing for a pointing gesture before he produces the directive (Figure 1). This finding is consistent with findings from previous studies on native speakers' speech and gestures in that the preparation for the gesture slightly precedes the coexpressive utterances (e.g., McNeil, 1992; Schegloff, 1984). At the point Bill produces the directive, he executes the pointing gesture: he extends his arm by leaning slightly forward and actually points to the object. In this way, he makes clear what he refers to through gaze and pointing. In other words, Bill uses both gestures 
and speech to establish a shared focus of reference. In response to Bill's action, Koma makes some movements that show his understanding of what is being talked about. At the beginning of line 3, Koma's eye gaze and his body orientation is directed at the speaker. However, at the point Bill finishes uttering kore, Koma turns his gaze to the referent, and by the time Bill finishes producing motte, Koma starts turning his body orientation to the referent (Figure 2). Thus, before Bill finishes uttering the directive, Koma's gaze is secured at the referent, and his body begins to face the referent. This shows that their mutual orientation to the referent had been established by Bill's gesture before his directive utterance was completed. In line 4, while asking the question kore donogurai aru wake? ("How much does this weigh?") of Bill, Koma turns his body completely to the referent and moves both his arms toward the referent. Then in line 5, while Bill is answering Koma's question kekkou omoi ("It's quite heavy"), Koma leans forward toward the referent. Finally in line 6, Koma complies with the directive: he lifts the referent up.

Almost the same phenomena can be observed in the second directive sequence (2).

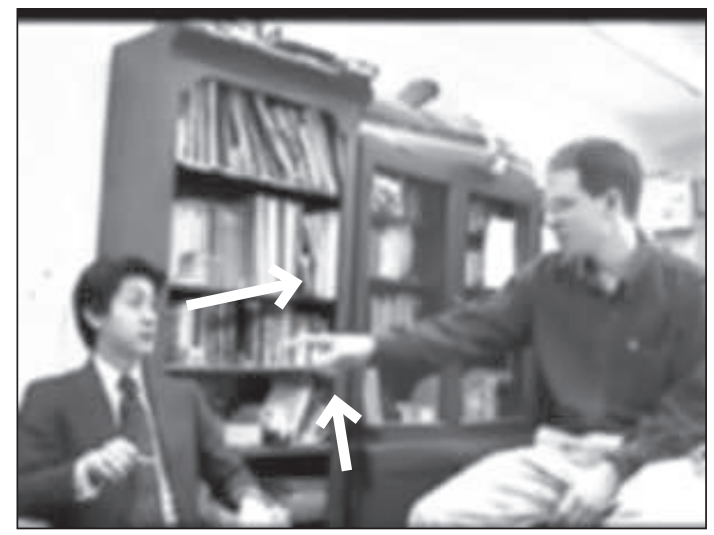

Figure 3. While Koma is producing "track (padget) track board," Bill starts looking at the object and starts raising his arm to point to the referent.

2. Koma: >track (padget)|track board.< "Track pad, track pad."

Bill:

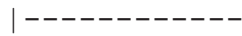

I ( gazes at the object and raises his arm to point to the object)) 


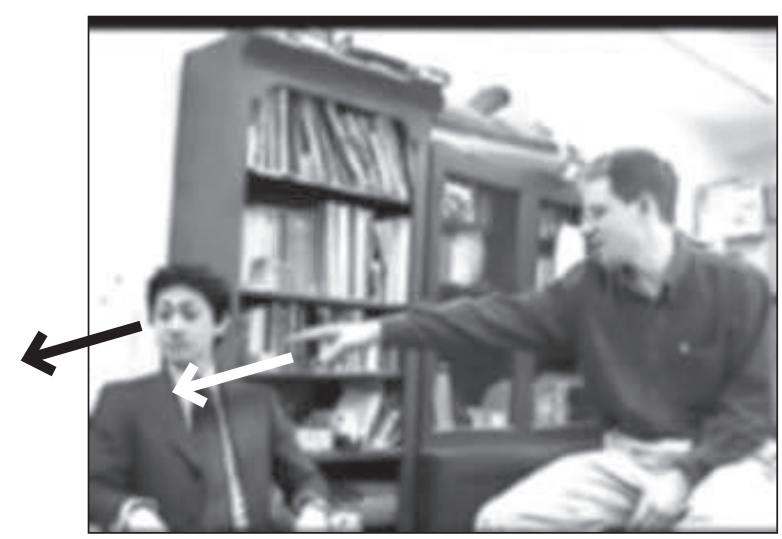

Figure 4. At the point Bill starts producing the directive, Koma begins turning his gaze to the referent.

3. Bill:|kore tsuka|tte mi|te.|Su|ggoi tsukai yasui.

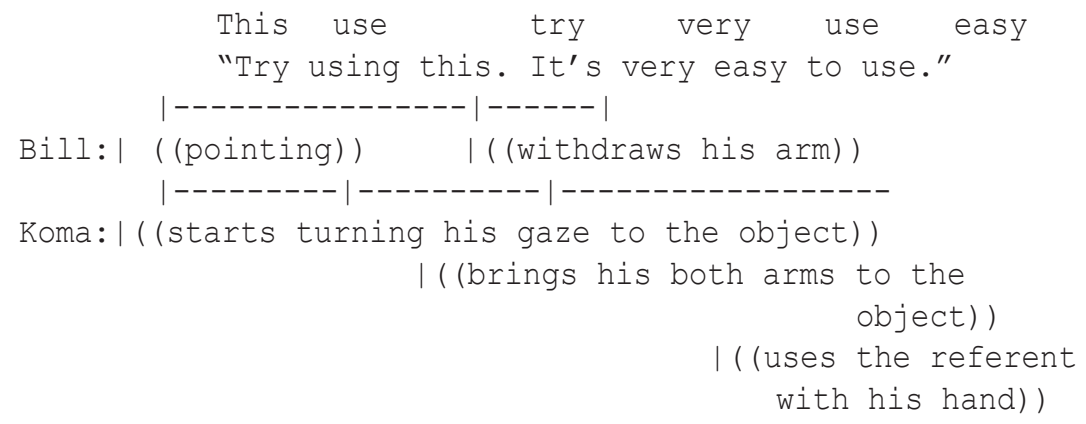

In line 2, while Koma is producing his line, Bill starts looking at the object and starts raising his arm to point to the referent (i.e., the trackpad on his computer) (Figure 3). Therefore, at the point Bill starts producing the directive, Koma begins turning his gaze to the referent (Figure 4). When Bill actually produces the directive in line 3, he extends his arm to point to the object. In other words, he displays his orientation to the referent by a gaze and pointing gesture. By the time Bill finishes the directive, Koma's hands are about to touch the referent. At the point Bill finishes the directive, Koma starts complying with the directive.

In the two examples above, Bill points to exactly the same object, his computer, which is on his desk along with various other things, and he refers to the referent using the same demonstrative pronoun kore ("this") 
instead of saying bokuno konpyutaa ("my computer"), which names the referent more explicitly. Moreover, grammatically speaking, Bill's use of kore is not appropriate. In Japanese, kore is used to refer to something close to the speaker, whereas sore is used to refer to something close to the addressee. In the examples above, Bill's computer is placed behind Koma and it is close to Koma but not close to Bill. Therefore, sore is more appropriate in this situation. However, in spite of Bill's ambiguous way of referring to the referent, Koma shows his understanding of Bill's directives by lifting up the correct referent in (1) and using the correct referent in (2). ${ }^{4}$

Similar phenomena can be observed in the third directive sequence, which is taken from the second data set.

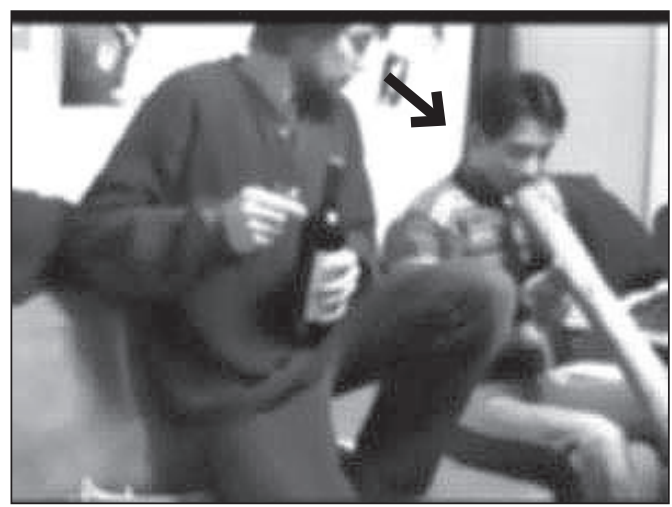

Figure 5. Before Gregg starts producing the directive, his gaze is already at the referent and Taro also turns his gaze to the referent by the end of the pause.

5. (1.8) ((Gregg begins to sit down next to Taro while looking at the instrument. Taro turns his gaze from Gregg to the instrument and brings it close to his mouth.))

6. Greg: ${ }^{\circ}$ yatte mi $\mid$ te. ${ }^{\circ}$

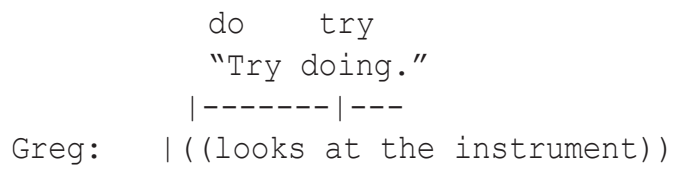




\section{Taro: |((holds the instrument closer to his mouth))}

\section{Taro: bwhohh bwhoohh ((plays the instrument))}

In line 5, during a 1.8-second pause, Gregg is looking at the referent (i.e., Taro's instrument) Taro is holding. Therefore, before Gregg starts producing the directive, his gaze is already at the referent. Taro, who was at first gazing at Gregg, also turns his gaze to the referent by the end of the pause (Figure 5). As Gregg starts producing the directive, Taro brings the referent closer to his mouth, and as soon as Gregg finishes producing the directive, Taro starts complying with the directive: he starts playing the instrument. What is intriguing in this example is that Gregg's directive in line 6 is uttered softly and it may not have been heard clearly by Taro. In addition, Gregg's directive sentence "try doing" does not have an object and it does not specify what Gregg wants Taro to do. Nevertheless, Taro shows his understanding of Gregg's directive by complying with the directive correctly.

In sum, in the three cases above, the following common phenomena were observed. First, before the speaker actually produced the directive, the speaker started gazing at the referent and prepared to point to the referent when there was a pointing gesture that accompanied the directive. In response to the speaker's gaze and gestures, the addressee immediately turned his gaze and body orientation to the referent. Thus, the speakers and the addressees established a shared focus of attention through gaze and their bodies before the speakers actually finished producing the directives. Second, although the speakers' ways of naming the referents were not explicit, the addressees displayed their understanding of the directives by complying with the directives immediately. The mutual understanding by the NSs and NNSs is also shown in the subsequent turns, in which they make some assessments on the referent, which I will address below.

\section{Making Assessments in Subsequent Turns}

The activity of doing assessments has been found to be the "central resource available to participants for organizing the perception and interpretation of what is being talked about" (Goodwin \& Goodwin, 
1987, p. 49). In the present data, the assessment sequences following the directives as well as compliance with the directives display the interactants' interpretation and understanding of the previous talk. Consider $(1)^{\prime}$ again with the focus on the latter part of the conversation.

(1)

3. Bill: =u:n. tt kore motte mite.

Uh-huh this have try

"Try lifting it up."

4. Koma: kore donogurai aru no.

This how much exist IP

"How much does this weigh?"

5. Bill: kekkou omoi.

Quite heavy

"It's quite heavy."

6. (.) ((Koma lifts the computer up.))

7. Koma: ah kore: niitengo kiro gurai aru $n$ zyanai? Oh this 2.5 kilogram about exist NR Cop:Tag "Oh, it weighs about $2.5 \mathrm{~kg}$, doesn't it?"

8. Bill: wakan nai kedo:

Know NEG but

"I don't know but,"

9. Koma: omoi. konna no mochi arui tara shigoto deki nai. Heavy such thing have walk if work able Neg "It's heavy. If I carry this around, I can't work."

10.Bill: shigoto dek(h) ih-=

work able:cont

"You can't work," 


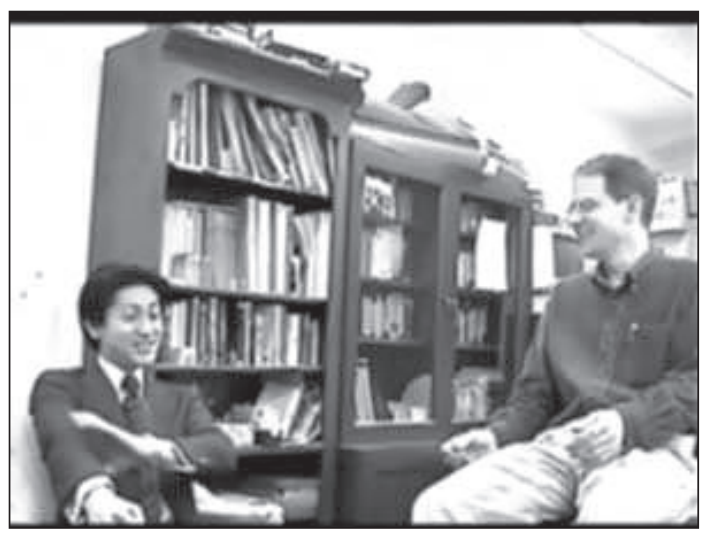

Figure 6. Koma says his arm muscle will be tight and strokes his arm.
11. Koma: | mou
$(0.4)$
ulde ga panpan ni|natyatte.
Well
arm Nom ONO
to become

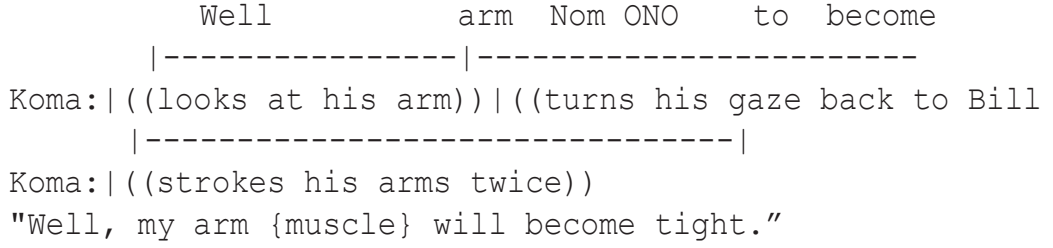

In this example, the participants, especially the recipient of the directive, make comments about a computer (i.e., the referent) in lines 7 to 11. It is about the heaviness of the computer and it is contingent on Bill's directive in line 3 as well as the talk before the directive. ${ }^{5}$ By doing assessments, Koma, the recipient of the directive, once again displays his understanding of the directive and surrounding talk. Therefore, these lines of assessment show that Bill (NNS)'s, directive was successful in making the weight of the computer visible and salient. Furthermore, Koma's action in line 11 demonstrates the inseparable nature of body and language. In line 11, when Koma says his arm muscles will be tight and strokes his arms (Figure 6), he is talking about the effect of the weight of the computer on the arms of a person carrying it. In other words, in making this comment, he is conceptualizing the interaction between the weight of the object and the human body through language.

In (2)' , although the assessment sequence is short, the interlocutors' mutual understanding can be seen. 
(2) '

3. Bill:|kore tuka|tte mi|te.|Su|ggoi tukai yasui.

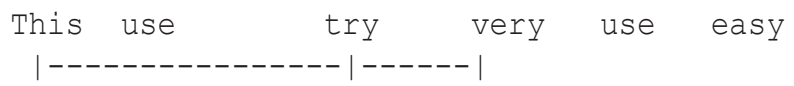

Bill:|((pointing to the object))

Bill: |( (withdraws his arm)) |---------|----------|------------------

Koma: | (turns his gaze to the object))

I((moves both his arms to the object))

I ( (uses the referent

"Try using this. It's very easy to use."

4. Koma: |honto da: :

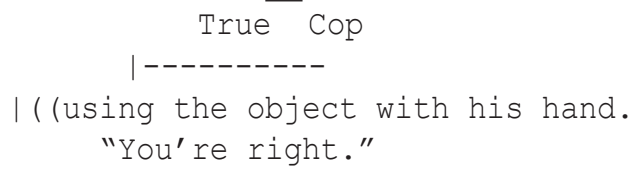

In line 3, Bill starts making an assessment on the referent (i.e., a track board on his computer) immediately after the directive. Koma, while using the referent with his hand, shows his understanding of Bill's directive and comment by agreeing with Bill. His agreement token honto da:: ("you are right") is strengthened with an emphatic stress at the end. In this example, the interlocutors are making an assessment on how easy it is for human hands to use the object. Therefore, again, they are expressing the interaction between the body and the object through language.

Finally, consider (3)' again with a focus on the part in which the interactants make assessments.

(3)'

6. Greg: 'yatte mite. ${ }^{\circ}$

$$
\begin{aligned}
& \text { Do try } \\
& \text { "Try doing." }
\end{aligned}
$$

7. Taro: bwhohh bwhoohh ((plays the instrument))

$$
\begin{aligned}
& \text { 8. chotto matte, } \\
& \text { a little wait } \\
& \text { "Wait a second." }
\end{aligned}
$$


12. Greg:

[hhuh hhuh hhuh kakko ii nhhuh nhhuh nhhuh Style good "It's cool."

13. hhuh hhuh]

14. Greg: kakko ii= Style good "It's cool."

15. Taro: =ii oto suru desyo: $i$ nice sound do Cop:Tag

"It makes a nice sound, doesn't it?"

16. Greg: ii oto suru nee.

nice sound do IP

"It makes a nice sound."

Following Gregg's directive in line 6, Taro starts playing the instrument in line 7. Then in lines 12 and 14, Gregg makes a comment kakko ii ("It's cool"). In line 15, Taro, who had stopped playing in line 13 makes a request for confirmation ii oto suru desho: ("It makes a nice sound, doesn't it?"). This comment on the sound of the instrument shows Taro's understanding that Gregg's directive in line 6 is a request to make a sound with the instrument and has nothing to do with its shape or weight. As a request for confirmation, this utterance by Taro makes agreement or disagreement relevant. In line 16, Gregg agrees with Taro. Thus, in this example, the interlocutors again express what the referent does to human bodies, specifically, to the ears.

In sum, through making assessments, the interactants displayed their understanding of the directives as well as what was going on in the prior turns. In addition, in making assessments on the referents, the interlocutors virtually transformed the weight, usability, and sound of the referents to the human body and thereby expressed the inseparable nature of the human body, objects, and language. 


\section{Conclusion}

This paper has demonstrated one way of looking at naturally occurring conversation to investigate NNSs' (as well as NSs') pragmatic competence and examined sequences of NNSs' directives that are jointly shaped by the NNSs and their interlocutors. First, it was shown that the NNSs' directives were dependent on previous talk and immediate settings, and the directives displayed the NNSs' competence in understanding the previous talk and the immediate environment in which the interactions were going on. Second, it was found that the NNSs and the NSs established a shared focus of attention through gaze and body movement before the NNSs actually finished uttering the directives. Third, even when the NNSs' ways of naming the referents were ambiguous, the NSs displayed their understanding of the directives by complying with the directives immediately. Accompanied gestures as well as sequential context helped to make the referent clear. This finding suggests that actions an utterance brings about are not coded solely by the linguistic forms of the utterance but rather, they are understood in the emerging sequential context in which bodily actions and language are crucially dependent on each other. Fourth, the NSs' compliance with the directives showed the NNSs' competence in carrying out the directive. Fifth, subsequent assessments also demonstrated the interactants' understanding of directives as well as what was going on in the prior turns. Finally, in their assessments the participants expressed the inseparable nature of the human body, objects, and language. In the directive sequences, the participants themselves demonstrated the relevance of speech, body, emerging sequential contexts, and the surrounding environment in producing and understanding directives.

In earlier studies, NNS's pragmatic competence was judged based on the NNSs' speech. However, as this initial study shows, in naturally occurring interaction, "competent" interlocutors juxtapose multiple resources with sequential organization, body, surrounding environment, and so forth' joining with speech to make meaning in interaction, and these nonlanguage resources may sometimes count for more than the linguistic appropriateness. Furthermore, the NNSs' pragmatic competence is displayed in sequences of actions that are realized collaboratively by both the NNSs and their interlocutors. In the future, research in NNS pragmatics needs to consider the collaborative nature of interaction and the range of resources the interactants deploy.

Finally, some teaching implications: In naturally occurring interaction, as participants use not only language but also other resources to 
accomplish actions and make meaning, second-language speakers may not focus their attention closely upon linguistic forms. Thus, the context of naturally occurring interaction may not be an ideal place for secondlanguage speakers to practice appropriate linguistic forms. Therefore, language classrooms are needed to provide learners with opportunities to focus on linguistic forms. On the other hand, learning a second language only in classrooms, which lack interactional contexts or real objects may not be enough to develop the competence necessary to deal with naturally occurring interaction. In order to equip themselves with sufficient pragmatic competence in a second language, learners may need to practice and learn the language in both language classrooms and in settings with naturally occurring interaction.

Yuri Hosoda, Ed. D. is an assistant professor at Kanagawa University. Her research interests include Conversation Analysis and second language teaching and learning.

\section{Notes}

1. For details on the larger set of data, see Hosoda (2002, 2003).

2. Therefore, although in the data the participants spoke mostly in Japanese, the two NSs of Japanese were advanced speakers of English.

3. In transcribing nonverbal features, | | is used to indicate overlapping of nonverbal behavior; and ----- is used to indicate continuation of the nonverbal feature. Nonverbal features of interlocutors are shown in lines below each sentence.

4. Koma's understanding may result from the fact that pointing gestures by themselves can be sufficient to constitute directives (Kelly et al., 1999).

5. Moreover, as second assessments were found to be upgraded (Pomerantz, 1984), in this example, the assessments are gradually upgraded. It starts from kekkou omoi ("It's quite heavy) by Bill (line 5), followed by omoi ("It's heavy") (line 9) and konna no moti arui tara sigoto dekinai ("If I carry this around, I can't work") by Koma, and finally ends with ude ga panpan ni natyau ("my arm \{muscles\} will become tight") by Koma.

\section{References}

Carroll, D. (2000). Precision timing in novice-to-novice L2 conversations. Issues in Applied Linguistics, 11(1), 67-110. 
Drew, P. (1984). Speakers' reportings in invitation sequences. In J. M. Atkinson, \& J. Heritage (Eds.), Structures of social action (pp. 152-164). Cambridge: Cambridge University Press.

Fiksdal, S. (1990). The right time and pace: A microanalysis of cross-cultural gatekeeping interviews. Norwood, NJ: Ablex.

Firth, A. (1996). The discursive accomplishment of normality. On 'lingua franca' English and conversation analysis. Journal of Pragmatics, 26, 237-259.

Goodwin, C. (1981). Conversational organization: Interaction between speakers and hearers. New York: Academic Press.

Goodwin, C. (2000). Action and embodiment within situated human interaction. Journal of Pragmatics, 32, 1489-1522.

Goodwin, C. (2003). Pointing as situated practice. In S. Kita (Ed.), Pointing: where language, culture and cognition meet (pp. 217-241). Mahwah, NJ: Lawrence Erlbaum Associates.

Goodwin, C., \& Goodwin, M. H. (1986). Gesture and coparticipation in the activity of searching for a word. Semiotica, 62(1/2) 51-75.

Goodwin, C., \& Goodwin, M. H. (1987). Concurrent operation on talk: Notes on the interactive organization of assessments. IPRA Papers in Pragmatics, 1(1) 1-54.

Hosoda, Y. (2002). Analyzing Japanese native-nonnative speaker conversation: Categories, other-repair, and production delay. Unpublished doctoral dissertation. Temple University.

Hosoda, Y. (2003). Language learning in ordinary communication between native speakers and nonnative speakers. The Japanese Journal of Language in Society, 6(1) 89-98.

Jefferson, G. (1984). On the organization of laughter in talk about troubles. In J. M. Atkinson and J. Heritage (Eds.), Structures of Social Action: Studies in Conversation Analysis (pp. 346-369). Cambridge: Cambridge University Press.

Kasper, G. (2000). Data collection in pragmatics research. In H. Spencer-Oatey (Ed.), Culturally speaking (pp. 316-369). New York: Continuum.

Kasper, G., \& Dahl, M. (1991). Research methods in interlanguage pragmatics. Studies in Second Language Acquisition, 12, 215-247.

Kasper, G., \& Rose, K. R. (2003). Pragmatic development in a second language. Oxford: Blackwell.

Kelly, S. D., Barr, D. J., Church, R. B., \& Lynch, K. (1999). Offering a hand to pragmatic understanding: The role of speech and gesture in comprehension and memory. Journal of Memory and Language, 40, 577-592.

Kita, S. (2003). Interplay of gaze, hand, torso orientation. In S. Kita (Ed.), Pointing: Where language, culture, and cognition meet (pp. 307-328). Mahwah, NJ: Lawrence Erlbaum Associates.

Markee, N. (2000). Conversation analysis. Mahwah, NJ: Lawrence Erlbaum Associates. 
Maxwell, J. A. (1996). Qualitative research design: An interactive approach. Newbury Park, CA: Sage.

Maynard, S. (1997). Japanese conversation. Honolulu: University of Hawai'i Press.

McNeil, D. (1985). So you think gestures are nonverbal? Psychological Review, 92(3), 350-371.

McNeil, D. (1992). Hands and mind. Chicago: University of Chicago Press.

McNeil, D. (2003). Pointing and morality in Chicago. In S. Kita (Ed.), Pointing: Where language, culture and cognition meet (pp. 293-306). Mahwah, NJ: Lawrence Erlbaum Associates.

Mori, J. (2002). Task design, plan, and development of talk-in-interaction: An analysis of a small group activity in a Japanese language classroom. Applied Linguistics, 23(3), 323-347.

Ohta, A. S. (2000a). From acknowledgment to alignment: A longitudinal study of the development of expression of alignment by classroom learners of Japanese. In K. R. Rose \& G. Kasper (Eds.), Pragmatics in language teaching (pp. 103-120). New York: Cambridge University Press.

Ohta, A. S. (2000b). Second language acquisition processes in the classroom. Mahwah, NJ: Lawrence Erlbaum Associates.

Pomerantz, A. (1978). Compliment responses: Notes on the co-operation of multiple constraints. In J. Schenkein (Ed.), Studies in the organization of conversational interaction (pp. 79-112). New York: Academic Press.

Pomerantz,A. (1984). Agreeing and disagreeing with assessments: Some features of preferred/dispreferred turn shapes. In J. M. Atkinson \& J. Heiritage (Eds.), Structures of social action: Studies in conversation analysis (pp. 57-101). Cambridge: Cambridge University Press.

Poole, D. (1992). Language socialization in the second language classroom. Language Learning, 42, 593-616.

Schegloff, E. A. (1984). On some gestures' relation to talk. In J. M. Atkinson \& J. Heritage (Eds.), Structures of social action: Studies in conversation analysis (pp. 266-296). Cambridge: Cambridge University Press.

Schegloff, E. A. (1988). On an actual virtual servo-mechanism for guessing bad news: A single case conjecture. Social Problems, 35(4), 442-457.

Schegloff, E. A. (1998). Body torque. Social Research, 65(3), 535-596.

Schegloff, E. A. (1999). Discourse, pragmatics, conversation analysis. Discourse Studies, 1(4), 405-435.

Searle, J. (1979). Expression and meaning: Studies in the theory of speech acts. Cambridge: Cambridge University Press.

Streek, J. (1993). Gesture as communication I: Its coordination with gaze and speech. Communication Monograph, 60, 275-299.

Wagner, J., \& Firth, A. (1997). Communication strategies at work. In G. Kasper \& E. Kellerman (Eds.), Communication strategies (pp. 323-344). London: Longman. 
Wong, J. (1994). A conversation analytic approach to the study of repair in native-nonnative speaker English conversation: The element "yeah" in same-turn repair and delayed next turn repair initiation. Unpublished doctoral dissertation, University of California, Los Angeles.

Wong, J. (2000a). Delayed next turn repair initiation in native/nonnative speaker English conversation. Applied Linguistics, 21, 247-297.

Wong, J. (2000b). The token "yeah" in nonnative speaker English conversation. Research on Language and Social Interaction, 33(1), 29-67.

(Received February 17, 2004; accepted July 15, 2004)

\section{Appendix A}

\section{Abbreviations and Transcription Conventions}

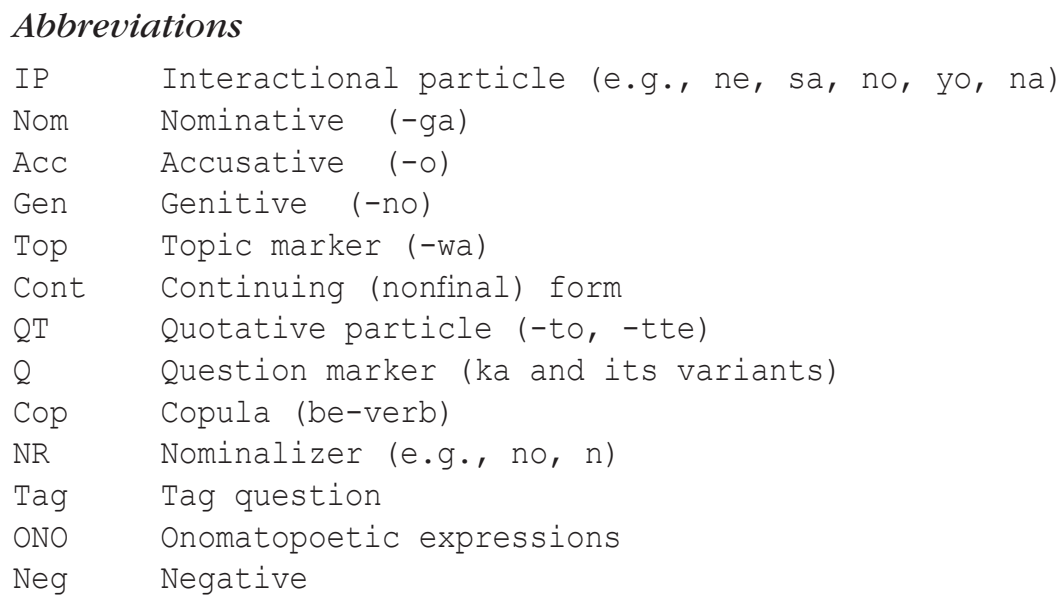

\section{Transcription Conventions}

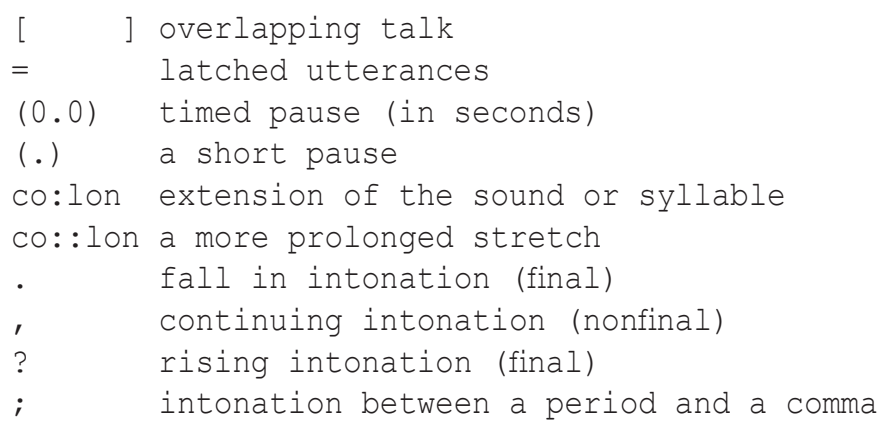


$\dot{c}$

a rise stronger than a comma but weaker than a question mark

CAPITAL loud talk

underline emphasis

个 sharp rise

sharp fall

passage of talk that is quieter than surrounding talk

$<>$ passage of talk that is slower than surrounding talk

$>\quad<\quad$ passage of talk that is faster than surrounding talk.

hh audible aspirations

*hh audible inhalations

(hh) laughter within a word

( ( ) ) comment by the transcriber

problematic hearing that the transcriber is not certain about

" " Idiomatic translation of Japanese utterances

\section{In idiomatic translation,}

words or phrases which are not explicitly stated in the Japanese versions.

\section{Appendix B}

(1) [Bill-Koma:3:59-62] Bill=NNS; Koma=NS

1. Koma: omo sugite nootobukku pasokon to wa ii gatai= heavy too notebook computer as Top say difficult

2. tokoro ga aru $n$ da yo ne.= place Nom exist NR Cop IP IP

"There is a good reason to say that it is too heavy to call it a notebook computer."

3. Bill: =u:n. tt kore motte mite.

Uh-huh this have try

"Uh-huh. Try lifting it up." 
4. Koma: kore donogurai aru no.

This how much exist IP

"How much does this weigh?"

5. Bill: kekkou omoi.

Quite heavy

"It's quite heavy."

6. (.) ((Koma lifts the computer up.))

7. Koma: ah kore: niitengo kiro gurai aru $n$ jyanai? Oh this 2. kilogram about exist NR Cop:Tag "Oh, it weighs about $2.5 \mathrm{~kg}$, doesn't it?"

8. Bill: wakan nai kedo:

Know Neg but

"I don't know,"

9. Koma: omoi. konna no mochi arui tara shigoto deki nai. Heavy such thing have walk if work able Neg "It's heavy. If I carry this around, I can't work."

10. Bill: sigoto dek(h)ih-= work able:Cont

"You can't work,"

11. Koma: =mou (0.4) ude ga panpan ni natyatte Well arm Nom ONO to become "Well, my arm (muscles) will become tight."

(2) [Bill-Koma:5:100-101] Bill=NNS; Koma=NS

((Just prior to this segment, Koma mentions about a track board of his notebook computer.))

1. Bill: track (padget) desyo?

Track (padget) Cop:Tag

"Track (padget), right?"

2. Koma: >track (padget) track board.<

3. Bill: kore tukatte mite. sugoi tsukai yasui. 


$$
\begin{aligned}
& \text { This use try very use easy } \\
& \text { "Try using this. It's very easy to use." }
\end{aligned}
$$

4. Koma: honto da: :

$$
\begin{aligned}
& \text { True Cop } \\
& \text { "You're right." }
\end{aligned}
$$

(3) [Gregg-Taro: 1:1-16] Gregg=NNS; Taro=NS

1. Taro: miru no hajimete;

Look NR first time

"Is it the first time you have seen it?"

2. Greg: hazimete. ah miru no wa jya nai kedo= First time oh look NR Top Cop Neg but "First time. Oh, it is not the first time I have seen it."

3. Taro: =a: hon[tou.]

$$
\begin{aligned}
& \text { Oh really } \\
& \text { "Oh, really." }
\end{aligned}
$$

4. Greg: [haji]mete jya nai yo. First time Cop Neg IP "It is not the first time."

5 .

$$
\text { (1.8) ((Gregg begins to sit down next to }
$$
Taro while gazing at the instrument. Toro turns his gaze from Gregg to the instrument and brings it close to his mouth.))

6. Greg: 'yatte mite. ${ }^{\circ}$

$$
\begin{aligned}
& \text { Do try } \\
& \text { "Try doing." }
\end{aligned}
$$

7. Taro: bwhohh bwhoohh ((plays the instrument))

8. chotto matte,

$$
\begin{aligned}
& \text { a little wait } \\
& \text { "Wait a second." }
\end{aligned}
$$

9. 
10. bwho000[000000000000000000000000000000000000000

11. 0000000000$] 0000000000000000000000000000000 \mathrm{hh}$

12. Greg: [hhuh hhuh hhuh kakko ii nhhuh nhhuh nhhuh Style good

"It's cool."

13. hhuh hhuh]

14. Greg: kakko ii=

Style good

"It's cool."

15. Taro: =ii oto suru desyo: $i$

Good sound do Tag

"It makes a good sound, doesn't it?"

16. Greg: ii oto suru nee.

Good sound do IP

"It makes a good sound." 
